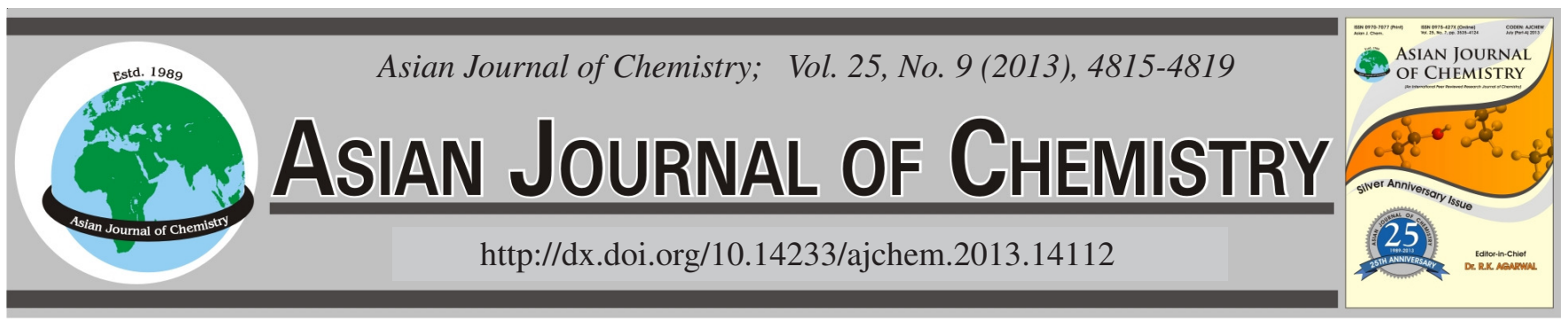

\title{
Selective Oxidation of Benzylic Alcohols with Molecular Oxygen Catalyzed by Copper-Manganese Oxide Nanoparticles
}

\author{
Roushown Ali, M.E. Assal, Abdulrahman Al-Warthan and M. Rafiq H. Siddiqui*
}

Department of Chemistry, College of Science, King Saud University, PO Box 2455, Riyadh-11451, Kingdom of Saudi Arabia

*Corresponding author: Tel: +966 14676082; E-mail: rafiqs@ksu.edu.sa

The catalytic activity of copper-manganese $(\mathrm{CuMn})$ mixed oxide nanoparticles $(\mathrm{Cu} / \mathrm{Mn}=1: 1)$ prepared by co-precipitation method has been studied for the selective oxidation of benzyl alcohol and its derivatives to the corresponding aldehydes using molecular oxygen as an oxidizing agent. A $100 \%$ conversion of the alcohols was achieved with high selectivity $(>99 \%)$ to the corresponding aldehydes within a short reaction period at $102{ }^{\circ} \mathrm{C}$. The best catalytic activity was obtained for the $\mathrm{CuMn}$ mixed oxide pre-calcined at $300{ }^{\circ} \mathrm{C}$. The catalytic performance is also obtained to be dependent on the electronic and steric effects of the substituents present on phenyl ring. The catalyst has been characterized with a combination of various characterization techniques.

Key Words: Copper-manganese oxide, Catalyst, Oxidation, Benzylic alcohols.

\section{INTRODUCTION}

The selective catalytic oxidation of alcohols to the corresponding aldehydes has been a subject of intense research as these transformations have significant impact for laboratory synthesis and industrial manufacturing ${ }^{1-4}$. Because of their extensive applications as an important precursor to pharmaceuticals and fine organics, the catalytic oxidation of benzylic alcohols to the corresponding aldehydes has received renewed interest over the last few decades. With an increasing environmental concerns, the selective oxidation of alcohols to the corresponding aldehydes with environmentally benign inexpensive oxidants, such as molecular oxygen has attracted great attention from both economic and environmentally point of view $w^{5-8}$. Although many studies have been reported using transition metal containing catalysts, but disadvantages of the catalysts are, use of complex ligands or expensive novel metals as supports/influence or difficult in preparation. Therefore, facile preparation method using inexpensive transition metals with a more selective and environmentally friendly system for the catalytic oxidation of benzylic alcohols to the corresponding aldehydes is still in demand.

Many efforts have been made to improve the catalytic activity and selectivity for this process, using primarily precious metal or metal-based compounds as catalysts, such $\mathrm{Au},{ }^{9,10} \mathrm{Pd}^{11,12}, \mathrm{Ru}^{13,14}$ and $\mathrm{Pt} .{ }^{15,16}$. These catalysts suffer from high cost and limited availability. Numerous studies have also been devoted to non-noble metals or metal-based catalysts, such as $\mathrm{Cu}^{17}, \mathrm{Ni}^{18}, \mathrm{Fe}^{19}, \mathrm{~V}^{20}, \mathrm{Co}^{21}, \mathrm{Ag}^{22}, \mathrm{Cr}^{23}, \mathrm{Mo}^{24}, \mathrm{Zn}^{25}$ and $\mathrm{Re}^{26}$ for oxidation of benzyl alcohol with molecular oxygen. Among the various abundant and low cost transition metals, $\mathrm{Cu}$ and Mn-containing compound as catalysts is continuing to inspire research for developing newer and green method for the selective oxidation of benzylic alcohols with molecular oxygen. There are some reports on Mn-containing catalysts for oxidation of benzylic alcohols using molecular oxygen, but those involved supports or ligands such as octahedral molecular sieves ${ }^{27-29}$, various kinds of alumina as support ${ }^{30-34}$, supported on cerium(IV) $)^{35}$, combination with TEMPO $(2,2,6,6-$ tetramethyl-piperidyl-1-oxyl) ${ }^{33,36}$. Mn(II) complexes ${ }^{37}$ immobilized in the pore channels of mesoporous hexagonal molecular sieves and hexadentate $\mathrm{Q}_{3} \mathrm{Mn}(\mathrm{III})$ complexes ${ }^{38}$ have been reported for oxidation of alcohols using TBHP and $\mathrm{H}_{2} \mathrm{O}_{2}$ as oxidant, respectively. Thus, there is renewed interest for searching inexpensive transition-metal catalyst with facile preparation method offering more activity and selectivity using molecular oxygen.

Recently we have reported ${ }^{39} \mathrm{CuMn}_{4}$ mixed oxide with $\mathrm{Cu} /$ $\mathrm{Mn}=1: 4$ for the oxidation of benzyl alcohol to benzaldehyde with molecular oxygen. Herein, we report an evaluation of the $\mathrm{CuMn}$ mixed oxide $(\mathrm{Cu} / \mathrm{Mn}$ molar ratio of $1: 1)$ as catalyst for the selective oxidation of benzyl alcohol and its derivatives with molecular oxygen. The effect of the catalytic activity on the substituents in the benzyl alcohols has been compared. The catalyst has been characterized with a combination of various characterization techniques, such as thermogravimetric 
analysis, powder X-ray diffraction, scanning electron microscopy, transmission electron microscopy, Brunauer Emmet Teller (BET) and Fourier transform infrared (FT-IR) spectroscopies.

\section{EXPERIMENTAL}

Catalyst preparation: The $\mathrm{CuMn}$ mixed oxide $(\mathrm{Cu} / \mathrm{Mn}$ $=1: 1$ ) nanoparticles were prepared by a facile co-precipitation method employing $\mathrm{Cu}\left(\mathrm{NO}_{3}\right)_{2} \cdot 3 \mathrm{H}_{2} \mathrm{O}, \mathrm{Mn}\left(\mathrm{NO}_{3}\right)_{2} \cdot 4 \mathrm{H}_{2} \mathrm{O}$ and $\mathrm{Na}_{2} \mathrm{CO}_{3}$ as described in previous paper ${ }^{39}$. All reagents used were analytical grade and purchased from MERCK and BDH Chemical Ltd. and used without further purification. The powder oxide was calcined at $300{ }^{\circ} \mathrm{C}$ in air for $12 \mathrm{~h}$ and used for oxidation reaction. The catalyst was prepared with the nominal composition of $\mathrm{CuMnOx}$ which is in good agreement with the chemical analysis result $\mathrm{Cu}_{1.00} \mathrm{Mn}_{1.005} \mathrm{O}_{\mathrm{x}}$.

Thermogravimetric analysis was carried out using PerkinElmer Thermogravimetric analyzer 7 . The temperature was raised from $25^{\circ} \mathrm{C}$ to $800{ }^{\circ} \mathrm{C}$ at a heating rate of $10^{\circ} \mathrm{C} \mathrm{min}{ }^{-1}$. $\mathrm{X}$-ray powder diffraction pattern was recorded on a diffractometer (Rigaku, Ulttima IV) at $40 \mathrm{kV}$ and $40 \mathrm{~mA}$ using $\mathrm{CuK}_{\alpha}$ radiation $\left(\lambda=1.54056 \AA\right.$ ) for samples pre-calcined at $300^{\circ} \mathrm{C}$. Diffraction data were collected from $5-70^{\circ}$ with continuous mode, scan speed $2.0 \mathrm{deg} \mathrm{min}^{-1}$, sampling width $0.02 \mathrm{deg}$. Scanning electron microscopy together with elemental analysis (Energy Dispersive X-Ray Analysis: EDX) analysis was conducted on Jeol-SEM model JSM 6360A (Japan). Transmission electron microscopy was carried out using Jeol TEM model JEM 1101. Surface area of the CuMn mixed oxide was measured using low temperature nitrogen adsorption by Brunauer-Emmett-Teller (BET) method on a NOVA 4200e surface area and pore size analyzer. The infrared spectrum was recorded as KBr pellets using a Parkin-Elmer 1000 FT-IR spectrophotometer. The IR spectrum recorded was in the region of 4000$400 \mathrm{~cm}^{-1}$.

Oxidation reaction and product analysis: The synthesized CuMn mixed oxide nanoparticles were tested for the catalytic activity of benzyl alcohol and some of its derivatives in liquid phase oxidation using molecular oxygen. The reactions were carried out in a three-necked flask connected with oxygen gas cylinder and condenser under atmospheric pressure. In a typical catalytic experiment, $300 \mathrm{mg}$ catalyst and $2 \mathrm{mmol}$ substrates were charged in $10 \mathrm{~mL}$ toluene as solvent. The mixture was then heated on an oil bath at $102^{\circ} \mathrm{C}$. Oxygen was bubbled at a flow rate of $20 \mathrm{~mL} \mathrm{~min}^{-1}$ into the mixture with continuous stirring using a magnetic bar. The reaction temperature was maintained at $101-103{ }^{\circ} \mathrm{C}$. A small amount of reaction mixture was collected after a certain time. The collected reaction mixtures were separated by centrifugation and the liquids were analyzed by gas chromatography (GC) on GC-7890A Agilent Technologies Inc. equipped with a flame ionization detector (FID) and a 19019S-001 HP-PONA column. The conversions of the alcohols and the selectivity to the corresponding aldehydes were calculated by the peak areas.

\section{RESULTS AND DISCUSSION}

Catalytic performance: Initially we examined the effect of calcination temperature on the catalytic performance of the $\mathrm{CuMn}$ mixed oxide nanoparticles pre-calcined at $300{ }^{\circ} \mathrm{C}$ and
$500{ }^{\circ} \mathrm{C}$ and found that catalyst pre-calcined at $300^{\circ} \mathrm{C}$ led higher performances in liquid phase selective oxidation of benzyl alcohol with molecular oxygen. Subsequently, oxidation reactions of benzyl alcohol derivatives were carried out over the $\mathrm{CuMn}$ mixed oxide pre-calcined only at $300^{\circ} \mathrm{C}$. In a preliminary test, $200 \mathrm{mg}$ of the CuMn mixed oxide was used as catalyst for $2 \mathrm{mmol}$ of benzyl alcohol. A $100 \%$ conversion of benzyl alcohol was obtained after $1 \mathrm{~h}$ with a specific activity of $10 \mathrm{mmol} \mathrm{g}^{-1} \mathrm{~h}^{-1}$ at $102{ }^{\circ} \mathrm{C}$. Under the same conditions, benzyl alcohol was converted into benzaldehyde with $100 \%$ conversion after $35 \mathrm{~min}$. in presence of $300 \mathrm{mg}$ catalyst with a specific activity of $11.43 \mathrm{mmol} \mathrm{g}^{-1} \mathrm{~h}^{-1}$. Thus, $300 \mathrm{mg}$ catalyst was used as an optimized amount for oxidation of benzyl alcohol and its derivatives.

To evaluate the scope of the CuMn mixed oxide as catalyst, oxidation reactions with various electron withdrawing and electron donating substituents on benzyl alcohol were carried out under the same conditions used for benzyl alcohol. Table-1 shows conversion of benzyl alcohol and its derivatives as a function of time. It can be seen that all alcohols converted completely $(100 \%)$ at different times, but the selectivity to the corresponding aldehydes remained unchanged (> $99 \%$ ) for all the reactions.

The conversion of substituted benzyl alcohol with electron donating $-\mathrm{CH}_{3}$ group attached to the phenyl ring proceed little faster than that of benzyl alcohol. For a complete conversion, time required for substrate having electron donating $-\mathrm{OCH}_{3}$ group on the phenyl ring is equal to that of benzyl alcohol (Table-1). On the other hand, attachment of electron withdrawing groups $\left(-\mathrm{NO}_{2},-\mathrm{Cl}\right)$ to the phenyl ring decrease the efficiency of the oxidation reaction and required longer time for a complete conversion compared with that of the benzyl alcohol. The results indicated that electron density on the phenyl ring played an important role in the reactivity of the oxidation reaction. Substituent $\left(-\mathrm{NO}_{2}\right)$ attached to the meta-position of the phenyl ring affects more than that of para-position. Steric hindrance is another important factor that affect the reactivity as bulky electron donating $-\mathrm{C}\left(\mathrm{CH}_{3}\right)_{3}$ and electron withdrawing $-\mathrm{CF}_{3}$ groups attached to the phenyl ring decreased the efficiency of the reaction. Therefore, it can be concluded that oxidation reaction catalyzed by $\mathrm{CuMn}$ mixed oxide is influenced by both electronic and steric effects.

Characterization of CuMn mixed oxide catalyst: The structure and morphology of the CuMn mixed oxide nanoparticles catalyst were studied with a combination of various characterization techniques. Thermogravimetric analysis is showing the thermal stability of the CuMn mixed oxide (Fig. 1).

TGA curve of the oxide showed no significant weight loss up to $450^{\circ} \mathrm{C}$, suggesting thermal stability of the compound up to $450{ }^{\circ} \mathrm{C}$. The loss of wt $\%$ in the temperature $25-300{ }^{\circ} \mathrm{C}$ is observed to be $4 \%$ which is due to removal of surfaceabsorbed water or bound water in the structure of the oxide. The presence of water in the catalyst was also detected by IR spectroscopy. The noticeable step of thermal decomposition is observed between $450^{\circ}$ and $615^{\circ} \mathrm{C}$ with a loss of wt. $\%$ 6.18. This loss of wt. may due to decomposition of $\mathrm{CuO}$ and $\mathrm{MnCO}_{3}$ and/or formation of $\mathrm{Mn}_{2} \mathrm{O}_{3}$ phase above $450{ }^{\circ} \mathrm{C}$. The total loss of weight observed to be $16.32 \%$ when the catalyst was heated up to $800{ }^{\circ} \mathrm{C}$. It can be concluded that the catalyst 


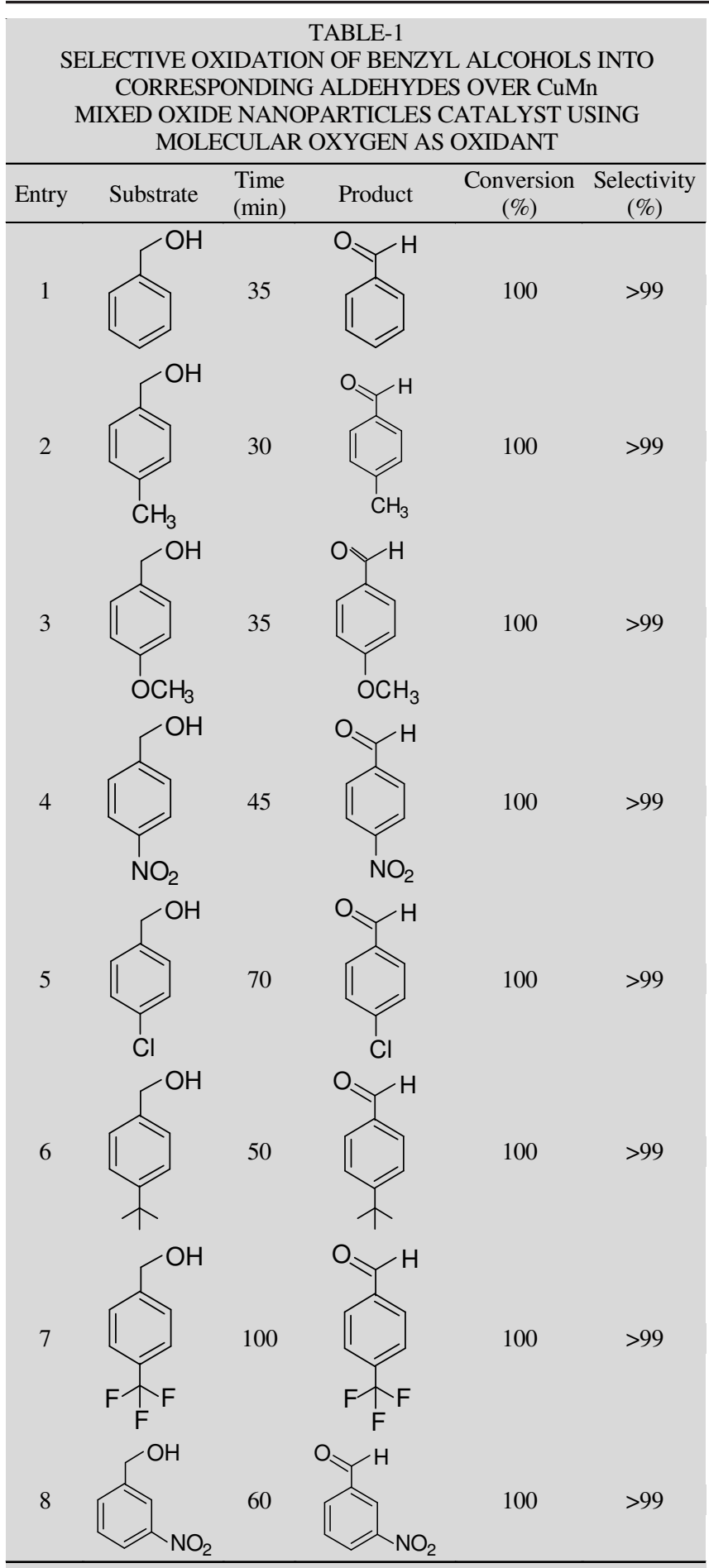

Reaction conditions: $300 \mathrm{mg}$ catalyst, $2 \mathrm{mmol}$ benzyl alcohol in $10 \mathrm{~mL}$ toluene, reaction temperature $102^{\circ} \mathrm{C}$

is thermally stable up to $300^{\circ} \mathrm{C}$ with the presence of two main phases $\mathrm{CuO}$ and $\mathrm{MnCO}_{3}$ as X-ray diffraction confirmed these two components.

X-ray diffraction pattern (Fig. 2) of the CuMn mixed oxide pre-calcined at $300{ }^{\circ} \mathrm{C}$ shows that the oxide consists of two major phases rhombohedral $\mathrm{MnCO}_{3}$ (ICSD \#80868) and monoclinic $\mathrm{CuO}$ (ICSD \#43180) and a minor cubic $\mathrm{CuMn}_{2} \mathrm{O}_{4}$ (ICSD \#93434) phase. Peaks of the corresponding phases are indicated by different symbols in Fig. 2. Some peaks of cubic $\mathrm{CuMn}_{2} \mathrm{O}_{4}$ phase are not apparent, but an influence in peak intensity/width of co-existing phase can be observed. The less visible peaks can be attributed to the formation of a little amount of $\mathrm{CuMn}_{2} \mathrm{O}_{4}$ phase and low intensity of the diffraction pattern. Most of the peaks that appear in the diffraction pattern are broad suggesting an amorphous nature or small particle size of the CuMn mixed oxide. This amorphous nature or small particle size may be attributed to the high catalytic activity of the catalyst.

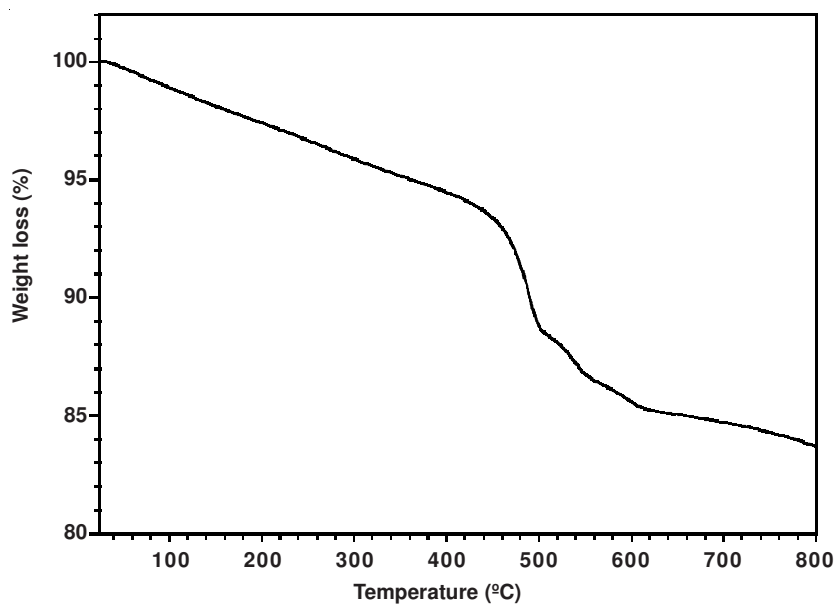

Fig. 1. TGA profile of CuMn mixed oxide

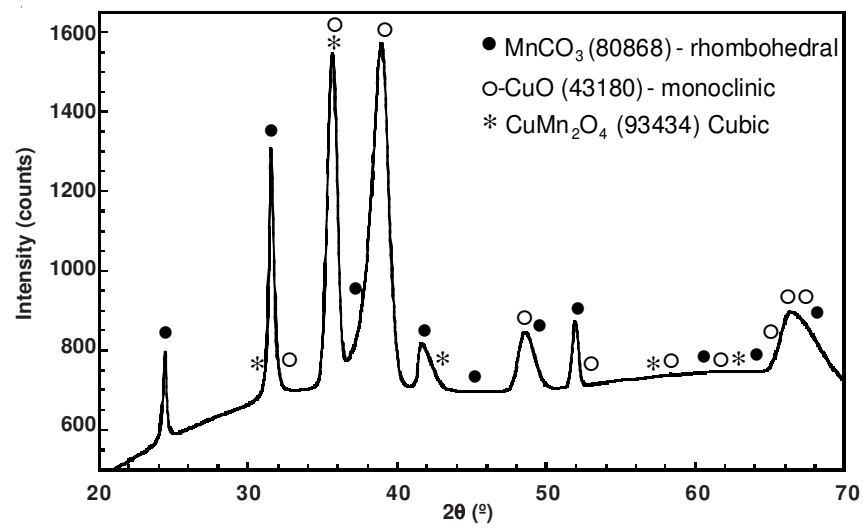

Fig. 2. Powder X-ray diffraction pattern of CuMn mixed oxide. Each symbol indicates peak of the corresponding phases

Fig. 3 shows image of scanning electron microscopy (SEM) of the CuMn mixed oxide calcined at $300^{\circ} \mathrm{C}$. A uniform spherical morphology with the average diameter being $\mathrm{ca} 1050$ $\mathrm{nm}$ was observed. To ascertain surface area of the $\mathrm{CuMn}$ mixed oxide BET analysis was carried out and obtained to be 101.86 $\mathrm{m}^{2} / \mathrm{g}$.

TEM image of the catalyst (Fig. 4) shows no indication of the existence of a unique phase and is not well crystalline. Copper and manganese oxides as well as other species were distributed over all the area. Particle size distribution calculated from the TEM image (Fig. 4) using Image $\mathrm{J} 1.44^{40}$ is shown in Fig. 5. Mean particle size was obtained to be 11.70 $\pm 0.02 \mathrm{~nm}$.

FT-IR spectra of the CuMn mixed oxide is shown in Fig. 6. The IR band appearing at $3420 \mathrm{~cm}^{-1}$ can be due to the presence of $\mathrm{OH}$ group and $\mathrm{H}_{2} \mathrm{O}$ as bound water in the structure. The absorption band at $1633 \mathrm{~cm}^{-1}$ corresponds to bending vibration modes of combined water molecules. The presence of absorption bands at 583 and $539 \mathrm{~cm}^{-1}$ may be assigned to vibration 
of $\mathrm{Cu}-\mathrm{O}$ in monoclinic $\mathrm{CuO}$. Morales et at. ${ }^{41}$ observed similar band in copper-manganese mixed oxide. Peak appeared at 861 $\mathrm{cm}^{-1}$ may be resulting from the distortion vibration of $\mathrm{CO}_{3}{ }^{2-}$. The characteristic bands at $\mathrm{ca} 672$ and $524 \mathrm{~cm}^{-1}$ for $\mathrm{Mn}_{2} \mathrm{O}_{3}{ }^{42}$ were not observed, suggesting the absence of $\mathrm{Mn}_{2} \mathrm{O}_{3}$ phase which is in agreement with the X-ray diffraction pattern.

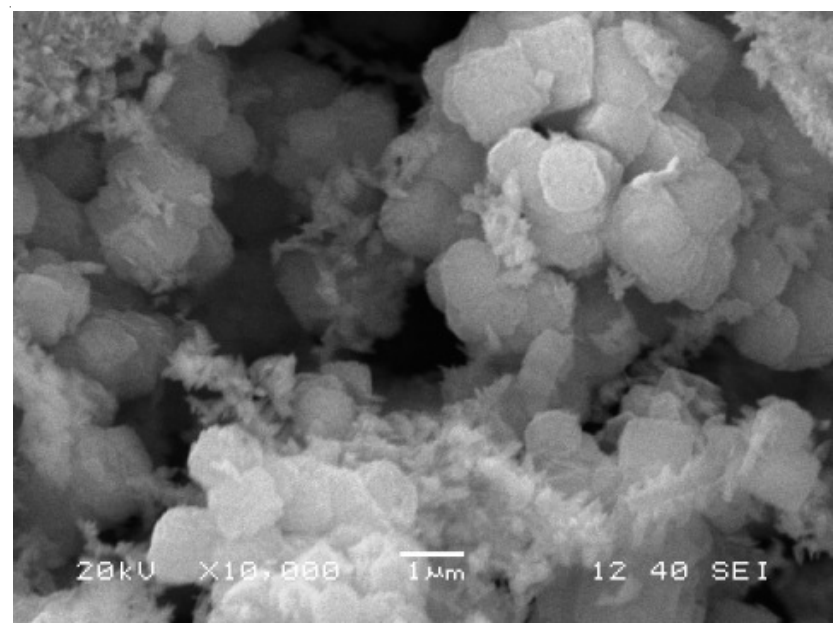

Fig. 3. Scanning electron microscopy image of CuMn mixed oxide precalcined at $300{ }^{\circ} \mathrm{C}$

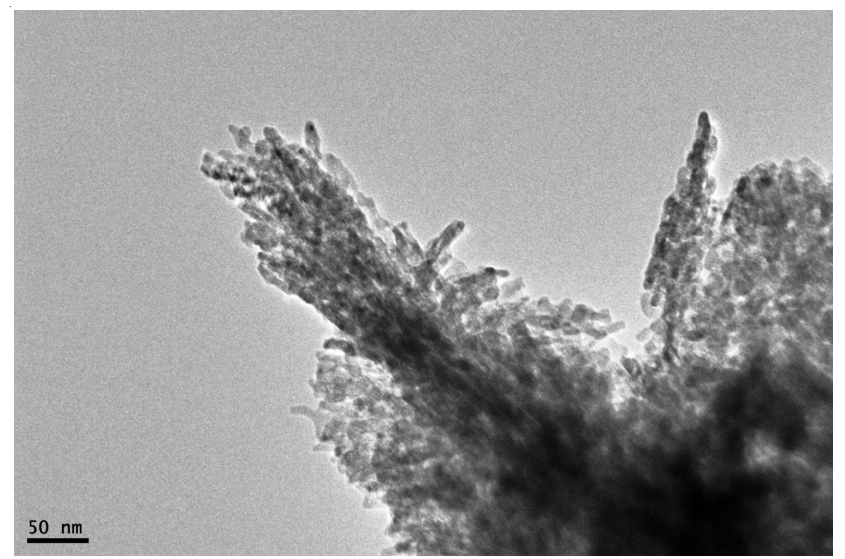

Fig. 4. Transmission electron microscopy image of $\mathrm{CuMn}$ mixed oxide pre-calcined at $300{ }^{\circ} \mathrm{C}$

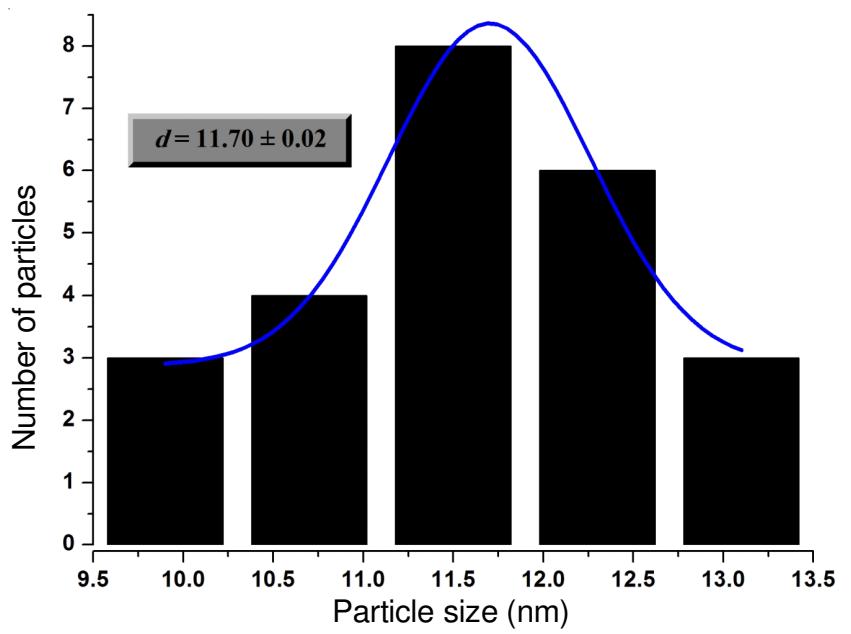

Fig. 5. Particle size distribution determined from TEM images of CuMn mixed oxide pre-calcined at $300{ }^{\circ} \mathrm{C}$

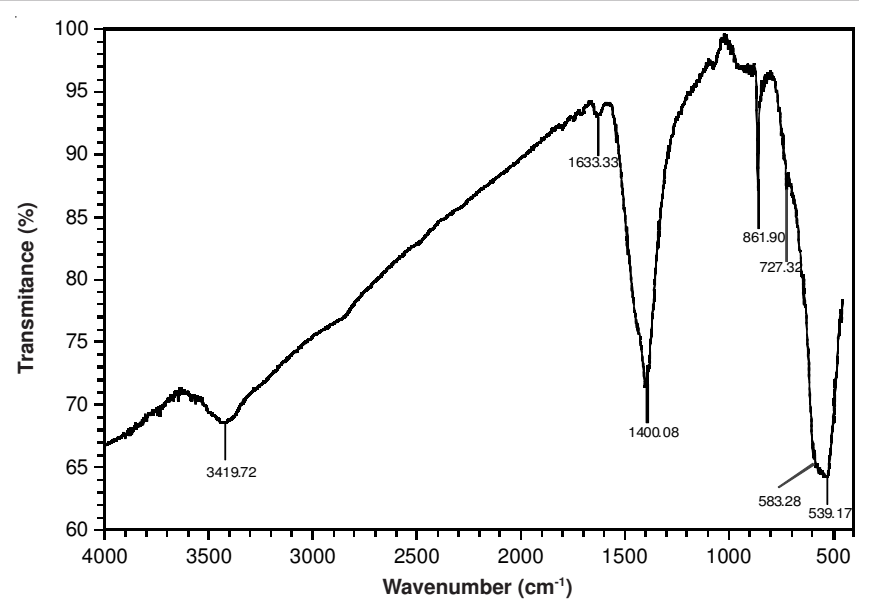

Fig. 6. Fourier transform infrared (FT-IR) spectroscopy of CuMn mixed oxide $(\mathrm{Cu} / \mathrm{Mn}=1: 1)$ pre-calcined at $300{ }^{\circ} \mathrm{C}$

\section{Conclusion}

The CuMn mixed oxide nanoparticles were prepared by a facile method and found to be highly selective catalyst for oxidation of benzyl alcohol to benzaldehyde using molecular oxygen. The CuMn mixed oxide provided high selectivity (> $99 \%$ ) to aldehyde at a complete conversion of benzyl alcohol. The catalyst also afforded $100 \%$ conversion with high selectivity (>99\%) to the corresponding aldehydes for the benzyl alcohol derivatives substituted with various electron donating $\left[-\mathrm{CH}_{3},-\mathrm{OCH}_{3},-\mathrm{C}\left(\mathrm{CH}_{3}\right)_{3}\right]$ and electron withdrawing $\left(-\mathrm{Cl},-\mathrm{NO}_{2}\right.$, $\left.-\mathrm{CF}_{3}\right)$ groups on the phenyl ring. The selectivity remained unchanged for all the reactions although the conversions were found to be affected by the substituent groups. Substrates having electron withdrawing and/or bulky groups required longer reaction time compared with those having electron donating groups on the phenyl rings.

\section{ACKNOWLEDGEMENTS}

This work is supported by the Research Center, College of Science, King Saud University, Riyadh, Kingdom of Saudi Arabia.

\section{REFERENCES}

1. D. Lenoir, Angew. Chem. Int. Ed., 45, 3206 (2006).

2. G. Tojo and M. Fernandez, in ed.: G.Tojo, Oxidation of Alcohols to Aldehydes and Ketones: A Guide to Current Common Practice, Springer, New York (2006).

3. T. Matsumoto, M. Ueno, N. Wang and S. Kobayashi, Chem. Asian J., 3, 196 (2008).

4. J. Fan, Y. Dai, Y. Li, N. Zheng, J. Guo, X. Yan and G.D. Stucky, J. Am. Chem. Soc., 131, 15568 (2009).

5. U.R. Pillai and E.S. Demessie, Green Chem., 6, 161 (2004).

6. B.Z. Zhan and A. Thompson, Tetrahedron, 60, 2917 (2004).

7. J.E. Backvall, Modern Oxidation Methods, Wiley-VCH (2004).

8. T. Mallat and A. Baiker, Chem. Rev., 104, 3037 (2004).

9. L.C. Wang, L. He, Q. Liu, Y.M. Liu, M. Chen, Y. Cao, H.Y. He and K.N. Fan, Appl. Catal. A, 344, 150 (2008).

10. V.R. Choudhary and D.K. Dumbre, App. Catal. A, 375, 252 (2010).

11. Y. Chen, H. Zheng, Z. Guo, C. Zhou, C. Wang, A. Borgna and Y. Yang, J. Catal., 283, 34 (2011).

12. Z. Hai, L. Ying and Z. Xungao, Chin. J. Catal., 32, 1693 (2011).

13. T. Yasueda, S. Kitamura, N. Ikenaga, T. Miyake and T. Suzuki, J. Mol. Catal. A, 323, 7 (2010).

14. H. Yu, Y. Zhang, X. Fu, F. Peng, H. Wang and J. Yang, Catal. Commun., 10, 1752 (2009). 
15. Y.M.A. Yamada, T. Arakawa, H. Hocke and Y. Uozumi, Angew. Chem. Int. Ed., 46, 704 (2007).

16. T. Mallat and A. Baiker, Catal. Today, 19, 247 (1994).

17. Y. Perez, R. Ballesteros, M. Fajardo, I. Sierra and I.D. Hierro, J. Mol. Catal. A: Chem., 352, 45 (2012).

18. S.R. Ali, P. Chandra, M. Latwal, S.K. Jain, V.K. Bansal and S.P. Singh, Chin. J. Catal., 32, 1844 (2011).

19. R. Naik, A. Nizam, A. Siddekha and M.A. Pash, Ultrasonics Sonochem. 18, 1124 (2011).

20. G.C. Behera and K.M. Parida, Appl. Catal. A: Gen., 413-414, 245 (2012).

21. S.M. Seyedi, R. Sandaroos and G.H. Zohuri, Chin. Chem. Lett., 21, 1303 (2010)

22. M. Deng, G. Zhao, Q. Xue, L. Chen and Y. Lu, Appl. Catal. B: Environ., 99, $222(2010)$

23. O.F. Ozturk, B.Z. Karan and S. Karabulut, Catal. Commun., 9, 1644 (2008).

24. P.S.N. Rao, K.T.V. Rao, P.S. Saiprasad and N. Lingaiah, Chin. J. Catal., 32, 1719 (2011)

25. S.R. Ali, V.K. Bansal, A.A. Khan, S.K. Jain and M.A. Ansari, J. Mol. Catal. A : Chem., 303, 60 (2009).

26. P. Paraskevopoulou, N. Psaroudakis, S. Koinis, P. Stavropoulos and K. Mertis, J. Catal. A: Chem., 240, 27 (2005).

27. S.L. Suib, Acc. Chem. Res., 41, 479 (2008).

28. F. Schurz, J.M. Bauchert, T. Merker, T. Schleid, H. Hasse and R. Glaser, Appl. Catal. A: Gen., 355, 42 (2009).
29. Y.C. Son, V.D. Makwana, A.R. Howell and S.L. Suib, Angew. Chem. Int. Ed., 40, 4280 (2001).

30. Q. Tang, X. Huang, C. Wu, P. Zhao, Y. Chen and Y. Yang, J. Mol. Catal. A: Chem., 306, 48 (2009).

31. Q. Tang, X. Huang, Y. Chen, T. Liu and Y. Yang, J. Mol. Catal. A: Chem., 301, 24 (2009).

32. Q. Tang, X. Gong, C. Wu, Y. Chen, A. Borgna and Y. Yang, Catal. Commun., 10, 1122 (2009).

33. G. Yang, W. Zhu, P. Zhang, H. Xue, W. Wang, J. Tian and M. Song, Adv. Synth. Catal., 350, 542 (2008).

34. Q. Tang, X. Gong, P. Zhao, Y. Chen and Y. Yang, Appl. Catal. A: Gen., 389, 101 (2010).

35. T. Sato and T. Komanoya, Catal, Commun., 10, 1095 (2009).

36. Y. Guo, J. Zhao, J. Xu, W. Wang, F. Tan, G. Yang and M. Song, J. Nat. Gas Chem., 16, 210 (2007).

37. V. Mahdavi, M. Mardani and M. Malekhosseini, Catal. Commun., 9, 2201 (2008).

38. Z. Ye, Z. Fu, S. Zhong, F. Xie, X. Zhou, F. Liu and D. Yin, J. Catal., 261, 110 (2009).

39. R. Ali, M.R. Siddiqui and A.A. Warthan, Oxidation Commun., 34, 778 (2011).

40. W. Rasband, Image J 1.44O, National Institutes of Health, Bethesda, Maryland, USA, http://imagej.nih.gov/ij/.

41. M.R. Morales, B.P. Barbero and L.E. Cadus, Fuel, 87, 1177 (2008).

42. X. Li, J. Xu, L. Zhou, F. Wang, J. Gao, C. Chen, J. Ning and H. Ma, Catal. Lett., 110, 149 (2006). 